\title{
DECOLONIALIDADE E DIFERENÇA EM "QUARTO DE DESPEJO": A DESCRIÇÃO DO COTIDIANO COMO FORMA DE RESISTÊNCIA
}

\author{
DECOLONIALITY AND DIFFERENCE IN "QUARTO DE DESPEJO": \\ THE DESCRIPTION OF EVERYDAY AS A FORM OF RESISTANCE
}

\author{
BASTOS, Natacha Pereira Alves ${ }^{1}$ \\ LIMA, Rogerio Mendes de ${ }^{2}$
}

\begin{abstract}
RESUMO
Uma das características da perspectiva decolonial consiste em assumir o lado dos oprimidos e suas diferentes formas de resistência à dominação. Nesse contexto, a obra "Quarto de despejo: diário de uma favelada", de Carolina Maria de Jesus, pode ser um importante instrumento de reflexão sobre o papel da narrativa crítica produzida pelos grupos oprimidos na construção de discursos e práticas contra-hegemônicas na América Latina. Partindo das anotações do referido livro e relacionando as vivências cotidianas da autora à realidade atual de parte das populações negras urbanas, este artigo pretende promover um diálogo sobre o tema da diferença a partir de uma perspectiva decolonial, sem perder de vista os campos dos estudos culturais e literários.
\end{abstract}

PaLAVRAS-CHAVe: "Quarto de despejo"; Diferença; Decolonialidade; Literatura; Diálogo.

\section{ABSTRACT}

One of the characteristics of the decolonial perspective is to give voice to the oppressed and their different forms of resistance to domination. In this context, the work "Quarto de despejo: diário de uma favelada" (In English: "Child of the Dark: The Diary of Carolina Maria de Jesus"), by Carolina Maria de Jesus, can be an important instrument for reflection on the role of the critical narrative produced by oppressed groups in the construction of counter-hegemonic discourses and practices in Latin America. Starting from the notes of the referred book and relating the author's daily experiences to the current reality of part of the black urban populations, this article intends to promote a dialogue on the theme of difference from a decolonial perspective, without losing sight of the fields of cultural and literary studies.

KEYWORDS: Difference; Decoloniality; Literature; Dialogue.

${ }^{1}$ Colégio Pedro II / Mestrado Profissional em Práticas de Educação Básica. Secretaria de Estado de Educação (SEEDUC-RJ). Rio de Janeiro, RJ, Brasil. ORCID: https://orcid.org/0000-0002-7498-9216 e-mail: bastos.natacha@gmail.com

${ }^{2}$ Colégio Pedro II / Mestrado Profissional em Práticas de Educação Básica. Rio de Janeiro, RJ, Brasil. ORCID: https://orcid.org/0000-0002-0437-5382 e-mail: mendeslimacp2@gmail.com 
DOI: $10.12957 / \mathrm{e}-\mathrm{mosaicos} .2020 .51960$

\section{INTRODUÇÃo}

A criação do grupo modernidade/colonialidade a partir dos anos 1990 e sua progressiva consolidação como um campo de estudos sobre diferentes fenômenos sociais na América Latina nas últimas décadas, tem provocado uma renovação teórico/prática nas abordagens sobre os discursos produzidos pelos grupos sociais e populações oprimidas no continente. Nesse sentido, textos que seriam silenciados ou considerados como manifestações exóticas ou singulares desses grupos, e, portanto, não disputariam espaço com as narrativas hegemônicas, são relidos como expressão da resistência às diferentes faces da dominação colonial, cujas bases são mantidas nas relações sociais latino-americanas mesmo com o fim da colonização.

Sendo assim, nesse artigo pretendemos refletir sobre a obra "Quarto de despejo: diário de uma favelada ${ }^{3 "}$ de duas formas. Como narrativa dos dominados sobre um cotidiano imposto socialmente que nega as condições básicas de sobrevivência para os sujeitos dominados e também como ato de resistência frente a essa realidade que possibilita o encontro de alternativas enunciativas e práticas contra hegemônicas.

Outro aspecto que desenvolveremos nesse artigo será o de relacionar os pensamentos e reflexões apresentadas pela autora com as abordagens sobre a diferença que valorizam a experiência do colonizado/dominado como lugar de produção de um olhar sobre o mundo (MACEDO e LOPES, 2011, p. 87). Diferença que não pode ser vista como justificativa para hierarquizar esse olhar, mas reconhecer que sua construção não deve ser pensada fora das relações de poder produzidas a partir dos processos históricos da modernidade e da colonização. (GROSFOGUEL, 2018).

Carolina Maria de Jesus nasceu em Sacramento, Minas Gerais e migrou com seus filhos para a primeira grande favela de São Paulo: Canindé. Trabalhou como catadora de lixo durante grande parte de sua vida. A partir da publicação de "Quarto de despejo", passa a ser reconhecida durante algum tempo e lança mais três livros. Contudo, isso não foi suficiente para que conseguisse romper com os padrões hegemônicos no campo da literatura. Gonçalves (2014, p. 24) alerta para o fato de o sucesso da autora no início dos anos 1960 é reconhecido através de termos como "a escritora favelada" ou a "voz da favela". Evidencia-se a operação das estruturas de dominação.

Apesar de ter sua obra traduzida para dezenas de países e ter se tornado um sucesso editorial, o lugar reservado a autora é o do "outro". A ênfase no termo favelada parece indicar a necessidade de não a incluir como parte do cânone literário. Além da obra que é objeto deste artigo, merecem destaque "Casa de alvenaria: diário de uma ex-favelada", no qual ela relata a mudança na sua condição social e a saída da favela e "Diários de Bitita" onde ela se remete à sua infância em Minas Gerais.

Penteado (2016, p. 20) afirma que esse alheamento tem relação com o incômodo provocado pela autora nos ambientes hegemônicos da crítica literária.

${ }^{3}$ DE JESUS, Carolina Maria. Quarto de despejo: diário de uma favelada. São Paulo: Ática, 2014. 
DOI: $10.12957 /$ e-mosaicos.2020.51960

Assumir que ela possa ser considerada "uma de nós" implica em romper com elementos centrais da dominação no campo da literatura:

Por isso, sua obra confunde e exige que o crítico saia de sua zona de conforto. Se Carolina não serve para o cânone, o cânone também não serve para Carolina. Não é de um guardião de autores e obras cultas que sairá a explicação para a complexidade da narrativa de uma catadora de papel que desafiou as normas sociais.

Lançado em 1960, "Quarto de despejo: diário de uma favelada" reúne diários de uma catadora de lixo, semianalfabeta, Carolina Maria de Jesus, que revelam a visão de dentro da favela ${ }^{4}$, que retrata o cotidiano da exclusão e seu impacto sobre os sujeitos $^{5}$. O nome "Quarto de despejo" é uma metáfora criada pela autora ao longo de seus escritos no livro em que despejo é o local onde lixos são jogados. No caso da favela, o lixo se refere às pessoas, aos pobres, que não cabem na cidade e são depositados na favela, como lixos. Assim, lixos e favelados se confundem na luta diária contra a fome. Nesse cenário, "o único perfume que exala [...] é a lama podre, os excrementos e a pinga" (p. 48).

A fome, as brigas recorrentes entre moradores, a violência interna à comunidade e o cotidiano de uma mãe solteira de três filhos é revelado a toda sociedade através da publicação de seu livro, que contempla seus escritos diários que fornecem multiplicidades de possibilidades para estudos sociais e culturais. As revelações da autora, permeadas por sentimentos de não-pertencimento à realidade vivenciada, possibilitam um diálogo intenso com discussões as quais problematizam a questão da diferença e da relação dominação/resistência.

Desse modo analisaremos como a obra "Quarto de despejo" é enunciativa e denuncia a dominação a partir da vivência de mulher, negra, favelada, ao mesmo tempo em que realiza um giro epistêmico e político, que rompe com a monocultura do saber (SANTOS, 2002) e caracteriza uma visão eurocêntrica de literatura.

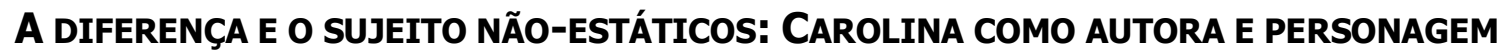

Por volta de 1990, as discussões sobre diversidade cultural de uma perspectiva pós-estruturalista ganham espaço nos diferentes contextos educacionais, culturais e políticos. Há uma crítica ao modo como as políticas de identidade e igualdade consolidaram a ideia de que diferença é algo negativo e deve ser rejeitado (MACEDO e LOPES, 2011, p. 86). A principal demanda desse posicionamento é colocar em xeque

40 termo "favela", adotado neste artigo, está distante de ser pejorativo. Antes disso, tal termo é defendido e enunciado pela autora do livro, Carolina Maria de Jesus, e expressa, assim, uma afirmação do local e da cultura pela própria. Logo, assumirei tal denominação, tomando como licença a enunciação da autora.

${ }^{5} \mathrm{O}$ material que deu origem ao livro foi produzido foi recolhido e publicado pelo jornalista Audálio Dantas e desde sua publicação original é exemplo da reflexão sobre a vida na favela produzida pelos seus moradores e não por pessoas externas ao espaço. 
o discurso hegemônico e utópico de uma igualdade, em termos sociais, econômicos que oprime qualquer menção à diferença como elemento constitutivo do sujeito, na medida em que as culturas não são estáticas e estão em permanente construção.

Por outro lado, considerando a necessidade de que essas identidades múltiplas sejam relacionadas à experiência da relação histórica com a dominação vivenciadas pelas populações negras, indígenas e latinas, a perspectiva decolonial entende que essas identidades devem ser vistas como uma resistência ao "particularismo disfarçado de universal" (COSTA, MALDONADO-TORRES \& GROSFOGUEL, 2018, p. 13) e o emergir da existência como produção de conhecimento.

Nessa perspectiva, Carolina: mãe solteira de três filhos/preconiza relacionamentos passageiros/semianalfabeta/catadora de lixo/negra/pobre/escritora... Diante de tantas facetas que Carolina se apresenta ao longo da obra, seria reducionista demais anunciá-la a partir de uma única face. Assim, a partir de seu posicionamento e de sua enunciação ao longo do livro, é perceptível notar seus múltiplos papéis na favela.

A própria linguagem utilizada pela autora e respeitada pelos editores, exemplifica a discussão que defendemos. Ao permanecer com erros de grafia e ortografia que ocorrem de maneira constante ao longo da redação, o livro possibilita uma enunciação e defesa das diferenças a partir de um lugar e de uma experiência que são ao mesmo tempo únicos e compartilhados. Únicos na medida em que representam uma reflexão sobre sua trajetória enquanto mulher histórica. Compartilhados, porque representam a seu modo, a vivência de outras mulheres negras.

Se por um lado, o respeito à linguagem utilizada pela autora e que foge dos padrões hegemônicos da escrita, pode indicar uma preferência dos editores, por outro, a difusão do seu texto permite que outra forma de descrever e refletir sobre o cotidiano seja trazida para o contexto da disputa dos discursos. De acordo com Hooks (2013, p. 22) na vida cotidiana "falamos de um jeito diferente com as diferentes plateias. Para nos comunicar melhor, escolhemos um jeito de falar determinado pelas particularidades e características únicas das pessoas com as quais falamos."

Ainda de acordo com Macedo e Lopes, a abordagem de uma estrutura não-fixa, descentrada, possibilita criação e mudança. De acordo com as autoras:

A concepção de uma estrutura descentrada e desestruturada permite entender a cultura e a linguagem como sistemas simbólicos dinâmicos, ainda constituídos por diferenças, mas por diferenças não estáveis, em contínua mutação. Nesse contexto, não se pode falar em diferentes ou identidades, já que diferenças mutantes não são capazes de gerar identidades; elas estão sempre apontando novas diferenças em um processo infinito. (MACEDO e LOPES, 2011, p. 88)

Logo, não é possível (nem desejável) encaixar Carolina, como personagem principal e autora, em uma caixa de pertencimento e defini-la apenas enquanto tal 
aspecto. Antes disso, Carolina demonstra-se plural, com um sentimento de não pertença nem à favela, nem à sociedade - no livro representada pelo centro da cidade. Ela, portanto, não apresenta uma autodefinição ímpar e exemplifica o sujeito não-fixo, que pertence a um contexto múltiplo e dinâmico, ainda que inconsciente. Contudo, é também um sujeito que rompe com padrões e produz um novo discurso sobre sua experiência singular e coletiva.

Gonçalves (2016, p. 27) destaca que a escrita da autora é parte de sua própria reconstrução enquanto pessoa, um modo de lidar e significar o sofrimento cotidiano. Na medida em que vivencia na São Paulo dos anos 1950, "a experiência inquietante da modernidade", Carolina é obrigada pela realidade cotidiana a passar por um processo de "individuação, de autonomia" que por conta das dificuldades materiais e simbólicas vividas "são definidoras de sua experiência que engendra seu sofrimento social". Assim, a escrita se transforma em sua forma de resistência, que ressignifica seu cotidiano e usa a fantasia para projetar, conscientemente, a superação de sua realidade.

Eu deixei o leito às 3 da manhã porque quando a gente perde o sono começa pensar nas misérias que nos rodeia. [...] Deixei o leito para escrever. Enquanto escrevo vou pensando que resido num castelo cor de ouro que reluz na luz do sol. Que as janelas são de prata e as luzes de brilhantes. Que a minha vista circula no jardim e eu contemplo as flores de todas as qualidades. [...] É preciso criar este ambiente de fantasia, para esquecer que estou na favela. Fiz o café e fui carregar água. Olhei o céu, a estrela D’alva já estava no céu. Como é horrível pisar na lama. As horas que sou feliz é quando estou residindo nos castelos imaginários (Quarto de despejo, p. 52)

Penteado (2016, p. 23) afirma que Carolina não pode ser inserida com facilidade nos modelos teóricos e literários disponíveis. Ela é "sujeito da narrativa, escreve o que pensa". Sua relação com seu editor e com seus leitores é de alguém que constrói seu discurso, que exerce seu direito à fala e constrói a partir de si seu próprio personagem. Coronel (2014, p. 272-273) alerta que uma das características da obra é "os recursos de linguagem que permitem à autora criar uma narrativa contundente acerca da experiência vivida, representando, por exemplo, a fome como uma vertigem amarela." Com esse modo de escrever, Carolina "reelabora a dor sentida por meio das palavras, que canalizam para a página o sofrimento, cristalizando-o além de si e do barraco que abriga a cena."

O conceito de colonialidade do poder (Quijano, 2009) indica que os padrões sociais de poder que sustentaram a dominação colonial, mantêm sua influência na vida social contemporânea das sociedades que foram colonizadas em todas as dimensões da vida. Com isso, impacta nos processos de leitura da realidade social pelos sujeitos.

Carolina não se sente em casa na favela, no local em que vive. O seu sentimento de não pertencimento fica evidente em vários trechos do livro. Além disso, o seu olhar mesmo que interno ao local, ocorre de maneira distinta: se sente como artista e, com 
isso, passa a enxergar às vivências da favela através de uma perspectiva crítica, com certa ironia, mas com desespero. "...Cheguei na favela: eu não acho geito de dizer que cheguei em casa" (p. 47). Além do sentimento de distanciamento do local da favela, mantém uma crítica direta aos moradores, vizinhos e ao próprio ambiente. "Eu falei que residia em favela. Que favela é o pior cortiço que existe" (p. 25).

Para a personagem, a negritude é um tema importante, mas não principal e tão constante em sua luta. A fome, a miséria, de acordo com sua perspectiva, é a principal luta que trava todos os dias, principalmente com sua filha Vera. Em um certo momento da narrativa, a autora relaciona a sua negritude, sua pobreza, ao dia de comemoração de libertação dos escravos: "Hoje amanheceu chovendo. É um dia simpático para mim. É o dia da Abolição. Dia que comemoramos a libertação dos escravos" (p. 30). Posteriormente, no decorrer do dia e através da sua busca incessante por comida, o início do dia, que era feliz por ser comemorado o dia da Abolição, torna-se um dia de amarguras e desesperos. Carolina, após a chuva, impossibilitada de catar papéis e com isso conseguir dinheiro para comprar comida para seus filhos, então, reflete: "Era 9 horas da noite quando comemos. E assim no dia 13 de maio de 1958 eu lutava contra a escravatura atual - a fome!" (p. 32). Logo, apesar de não haver mais escravidão, de não haver mais o colonialismo, Carolina ainda se sente presa à sua condição de negra, pobre, sofredora e a condição de miséria a qual sobrevive. Por muitas vezes, a autora associa a fome à questão racial, com uma proximidade para a cor do sofrimento, da fome. "Quando puis a comida o João sorriu. Comeram e não aludiram a cor negra do feijão. Porque negra é a nossa vida. Negro é tudo que nos rodeia" (p. 43).

Lima (2015) alerta para a existência de duas dimensões da dominação racial no Brasil. Uma material e outra subjetiva. Ambas podem ser percebidas na escrita de Carolina onde a realidade material ajuda a construir a subjetividade que tenta se afastar das dificuldades concretas da existência.

Nesse sentido, uma saída para Carolina é a arte de escrever. De acordo com a autora: "Quando eu não tinha nada o que comer, em vez de xingar eu escrevia. Tem pessoas que, quando estão nervosas, xingam ou pensam na morte como solução. Eu escrevia o meu diário" (p. 195). Através de sua escrita, por vezes dura e sofrida, mas também poética e denunciativa, a autora traduz em palavras o seu sofrimento, e por ser vivido, possibilita aos leitores enxergar o cotidiano de uma favela, sob a perspectiva real do próprio favelado. A escrita apresenta-se como uma forma de resistência à dominação, demonstrando que as estratégias de enfrentamento podem ser múltiplas.

O retrato da vida miserável dos negros em uma favela paulista, descrita por uma mulher negra e com uma linguagem distante dos cânones e dos discursos culturais e políticos sobre a vida das populações negras, levou muito tempo para ser reconhecido como referência em uma literatura cultural popular e urbana. Contudo, entendemos que traz nele um potencial contra hegemônico. De acordo com Meihy,

Em primeiro lugar seus escritos como manifestação formal. Seus erros gramaticais, em contraste com a difícil explicação de seu vocabulário, representam facetas que fundem na necessidade expressiva a afetação 
DOI: $10.12957 / \mathrm{e}-\mathrm{mosaicos} .2020 .51960$

de quem vê a literatura como poder. Isso, aliás, nunca esteve ausente da percepção de Carolina, que, mesmo sendo mulher fisicamente indefesa na favela, sabia que, por saber ler e escrever, tinha domínio dos códigos dos poderosos (MEIHY, 1998, p. 91).

Palma (2017, p.18-19) compreende "Quarto de despejo" como resistência e reescrita da própria trajetória. Nesse aspecto, a criação dos filhos, sua proteção da violência da favela e a garantia de que não passem fome se revela com uma forma de enfrentamento da realidade opressora. Contudo, é na relação com seu corpo que é produzida uma dualidade de significados que exemplifica em alguns momentos, o conformismo com a dominação "não ligo", "já estou acostumada" e em outros como defesa de sua identidade "Quando alguem nos insulta é só falar que é da favela. Nos deixa em paz. Percebi que nós da favela somos temido" (Quarto de despejo, p. 84)

Define-se assim que a obra não pertence a uma literatura dita como culta, escrita por escritores brancos sobre a vida de um negro - como por muito visto na nossa literatura nacional. "Quarto de despejo" revela o íntimo de uma mulher negra que, embora não conhecesse todas as regras gramaticais, enxergava e transbordava através de seus escritos sentimentos de reflexão e crítica à esfera social e política que a circundava.

O compromisso com essa e outras formas de resistência construídas pelos dominados ao longo dos últimos séculos, deve ser o mote da visão decolonial. ' $O$ deslocamento do projeto decolonial da luta política das populações negras, caso se concretizasse, seria uma traição à própria decolonialidade " (COSTA, MALDONADOTORRES \& GROSFOGUEL, 2018, p. 13). Seria um equívoco não considerar a obra "Quarto de despejo" como parte dessa luta, visto que como temos reforçado ao longo desse texto, enuncia uma realidade de dominação ainda presente em nossa sociedade. Mais que isso, aponta para o rompimento com uma tradição escrita hegemônica que silencia os discursos das populações dominadas.

Assim, a obra de Carolina, com toda sua riqueza e denúncia, é acessada através de uma perspectiva em que o culto, o intocável, já não mais existe, em que a literatura é uma forma de libertação e próxima, possível a todas as classes sociais, às pessoas advindas de todos os contextos. A autora, ao escrever, não se posiciona apenas como negra, mas como mulher, negra, catadora de lixo, pensadora, e toda a sua subjetividade e resistência que emerge junto à sua obra.

\section{Denúncia PRESENTE: a América Latina COMO local enUnCiATIVo}

De acordo com Escobar (2014), "América Latina es la única región del mundo donde actualmente se pueden estar desarrollando ciertos processos contrahegemónicos a nível del Estado"(p. 59). Assim, nossa luta deve ser política e epistêmica. Ou seja, a Amérina Latina é o local em que a luta pode e deve acontecer, tendo em vista os anos de colonialismo e a persistente colonialidade que vigora até os dias atuais. 
DOI: $10.12957 / \mathrm{e}-\mathrm{mosaicos} .2020 .51960$

A denúncia e a perspectiva reveladas a partir da leitura de Carolina, não pretendem, inicialmente, alcançar limites tão longes, na visão por vezes enunciadas pela autora. Entretanto, a partir de uma reflexão teórica da obra, podemos perceber que seu olhar de colonizado, de dominado, assume uma postura de denúncia ao tornar visível a face silenciada da fome, da miséria, existente nas favelas do Brasil nas décadas de 1950 e 60 . Assim, a produção do saber a ser promovida pelo colonizado, em suas múltiplas subjetividades, possibilita o conceito que vem instigado discussões culturais o "giro a la izquierda", em que provoca mudanças na relação entre produção do conhecimento, que ocorre, cada dia mais através da experiência e sofrimento dos colonizados, e se coloca como agenda política e social.

Carolina, expõe toda a sua dor e sofrimento com a intenção inicial de divulgar à sociedade o contexto interno da favela, as práticas sociais e as lutas diárias praticadas pelos favelados. Entretanto, a autora perpassa o limite de apenas denúncia para chegar a uma agenda de luta, na medida em que torna a literatura possível àqueles que pretendem. 0 poder de fazer literatura torna-se próximo aos favelados, com grande força expressiva, pretende chegar à liberdade através de seus escritos, uma vez que "as pessoas instruídas vivem com mais facilidade" (p. 195).

Logo, através da literatura, a autora sente-se livre, luta por saídas, vê através de palavras sua vida passageira, em que a realidade da favela em que vive, será denunciada através de seus diários, de seus escritos. Além de sonhar com outras realidades, deseja distância da favela, deseja denunciar através de suas palavras e tem consciência que iria "angariar inimigos, porque ninguém está habituado a esse tipo de literatura. Seja o que Deus quiser. Eu escrevi a realidade" (p. 197).

O processo de escrita e leitura realizado por Carolina, perpassa os muros de seu barraco e os limites da favela. De acordo com a autora:

Enquanto escrevo vou pensando que resido num castelo cor de ouro que reluz na luz do sol. Que as janelas são de prata e as luzes de brilhantes. Que a minha vista circula no jardim e eu contemplo as flores de todas as qualidades. [...] É preciso criar este ambiente de fantasia, para esquecer que estou na favela. [...] As horas que sou feliz é quando estou residindo nos castelos imaginários (JESUS, 2014, p. 60-61).

Dialogando com as proposições de Homi Bhabha, o qual afirma que a experiência por nós experimentadas é marcada por "uma tenebrosa sensação de sobrevivência, de viver nas fronteiras do 'presente"' (BHABHA, 2001, p. 19), na qual existe constantemente a sensação de uma subjetividade pertencente a diversos espaços e tempos, que produzem figuras complexas e que dialogam e resistem nos "entre-lugares"; lugares estes que são fronteiras para novos pensamentos, novas enunciações, que possibilitam articulações entre o passado e o presente, promovidas pelas diferenças, promovendo, assim, novos conhecimentos. De acordo com o teórico inglês, 
DOI: $10.12957 / \mathrm{e}-\mathrm{mosaicos} .2020 .51960$

A significação mais ampla da condição pós-moderna reside na consciência de que os "limites" epistemológicos daquelas ideias etnocêntricas são também as fronteiras enunciativas de uma gama de outras vozes e histórias dissonantes, até dissidentes - mulheres, colonizados, grupos minoritários, os portadores de sexualidades policiadas. [...] É nesse sentido que a fronteira se torna o lugar a partir do qual algo começa a se fazer presente em um movimento não dissimilar ao da articulação ambulante, ambivalente, do além que venha traçando. (BHABHA, 2011, p. 23-24)

O sentimento de não pertencimento que perpassa a obra e mesmo a crítica ao comportamento dos negros da favela, pode servir como parâmetro para a reflexão das populações negras de hoje. Ainda confinadas à favela, ver na escrita de uma de suas representantes sua própria realidade cotidiana, talvez signifique para essa população o estímulo para o questionamento das relações sociais que explicam as questões materiais e subjetivas que a obra levanta.

Outras experiências e saberes são possíveis: a dos dominados. Os colonizados possuem marcas de dominação, se encontram na fronteira da modernidade. Logo, não há como negar nem a existência da modernidade nem a relação de dominação que persiste. A possibilidade anunciada é de que, a partir das fronteiras, sejam possíveis novos conhecimentos, como uma reposta, como uma ação decolonial ${ }^{6}$, seguindo na direção oposta à hegemonia. Neste sentido, a literatura torna-se possibilidade de enunciação e contribuição para novas formas de conhecimentos. É preciso, então, decolonizar.

Nesse aspecto, obras como as de Carolina Maria de Jesus, que resgatem e valorizem as experiências e as múltiplas formas de resistência indígenas e afrobrasileiros podem ser ferramentas para que a literatura reconheça a "ecologia de saberes" (SANTOS, 2002, p. 250) que permite "não só superar a monocultura do saber científico, como a ideia de que os saberes não científicos são alternativos ao saber científico". Adotar essa postura, implica em reconhecer que o conceito de obras literárias é bem mais amplo do que o cânone eurocentrado representa e que há diferentes maneiras de uso da escrita para dialogar com a realidade.

\section{CONSIDERAÇÕES FINAIS}

"Quarto de despejo: diário de uma favelada", de Carolina Maria de Jesus, ao anunciar uma nova experiência literária através da enunciação da subjetividade de uma autora até então excluída do cânone literário, traz com sua publicação um giro na literatura e quiçá nos estudos culturais, se o tomarmos como partida para análise. Pretendemos, através deste artigo, utilizar-nos das falas de Carolina, enquanto autora

6 A Pedagogia Decolonial, proposta por Catherine Walsh, se propõe a uma ação, e não apenas ao reconhecimento das relações de dominação existentes. 
DOI: $10.12957 / \mathrm{e}-\mathrm{mosaicos} .2020 .51960$

e personagem, através de citações, para propor diálogos e conversas com certos conceitos referidos à perspectiva decolonial e aos estudos culturais.

Seis décadas depois de sua publicação, a reflexão sobre a obra colabora na compreensão da proposta decolonial e seu compromisso com as populações negras, indígenas e latinas. Permite questionar as consequências da persistência de modelos herdados e construídos com a exploração colonial. Contudo, mais que isso, é um espaço para que os dominados possam desvelar sem filtros sua própria realidade, 0 que pode levar à produção de novos discursos e práticas contra hegemônicas, essenciais para o enfrentamento das múltiplas formas de dominação.

A personagem Carolina não pertence a um passado ou presente fixo, além disso, não se sente pertencente a um local determinado, antes disso, sente-se em um espaço atemporal e informada com o contexto que a cerca. Assim, é possível relacionar o sentimento da autora/personagem às discussões do entre-lugar, propostas por Bhabha e a uma reflexão sobre a fronteira, sendo o local onde novos conhecimentos são possibilitados, e por que não, novas histórias possam ser construídas.

\section{REFERÊNCIAS}

BHABHA, Homi. O local da cultura. Belo Horizonte: Editora UFMG. 2001.

CANCLINI, N. G. Culturas híbridas, poderes oblíquos. In: CANCLINI, N. G. Culturas Híbridas: estratégias para entrar e sair da modernidade. São Paulo: EdUSP, 2011. p. 283-350.

CORONEL, Luciana Paiva. A censura ao direito de sonhar em Quarto de despejo, de Carolina Maria de Jesus. Estud. Lit. Bras. Contemp., Brasília, n. 44, p. 271-288, dez. 2014.

DE JESUS, Carolina Maria. Quarto de despejo: diário de uma favelada. São Paulo: Ática, 2014.

ESCOBAR, A. America Latina en una encrucijada: ¿modernizaciones alternativas, posliberalismo o posdesarrolo? In: QUINTERO, P. Crisis Civilizatoria, Desarrollo y Buen Vivir. Buenos Aires: Del Signo, 2014. p. 59-105.

GONCALVES, Marco Antonio. Um mundo feito de papel: sofrimento e estetização da vida (os diários de Carolina Maria de Jesus). Horiz. antropol., Porto Alegre, v. 20, n. 42, p. 21-47, dez. 2014.

GROSFOGUEL, Ramon. Para uma visão decolonial da crise civilizatória e dos paradigmas da esquerda ocidentalizada. In: COSTA, Joaze B. MALDONADO_TORRES, Nelson. GROSFOGUEL, Ramon. Decolonialidade e pensamento afrodiaspórico. 1. Ed. Belo Horizonte. Autêntica Editora. 2018 
DOI: $10.12957 / \mathrm{e}-\mathrm{mosaicos} .2020 .51960$

HOOKS, Bell. Ensinando a transgredir. São Paulo. Martins Fontes. 2013.

LIMA, Rogerio M. Educação intercultural e combate ao racismo. in Criatividade e Interculturalidade, volume 1. / Kátia Regina X. Pereira da Silva e Flávia Vieira da Silva do Amparo (organizadoras). - Curitiba: CRV, 2015.

MACEDO, E; LOPES, A. Cultura. In: MACEDO, E; LOPES, A. Teorias de Currículo. Rio de Janeiro: Eduerj: 2011. p.87-102.

MEIHY, José Carlos Sebe Bom. Carolina Maria de Jesus: emblema do silêncio. Revista USP, n. 37, p. 82-91, 1998.

PALMA, Daniela. As casas de Carolina: espaços femininos de resistência, escrita e memória. Cad. Pagu n.51 Campinas 2017 Epub 18-Dic-2017

PENTEADO, Gilmar. A árvore Carolina Maria de Jesus: uma literatura vista de longe. Estud. Lit. Bras. Contemp., Brasília, n. 49, p. 19-32, dez. 2016.

QUIJANO, Aníbal. Colonialidade do poder e classificação social. In: Epistemologias do Sul / org. Boaventura de Sousa Santos, Maria Paula Meneses - (CES). 2007. Capítulo 2.

WALSH, Catherine. Interculturalidade Crítica/Pedagogia decolonial. In: Educação Intercultural na América Latina: entre concepções, tensões e propostas. Bogotá: Universidad Pedagógica Nacional 17-19 de abril de 2007.

Recebido em 22 de junho de 2020

Aceito em 10 de outubro de 2020

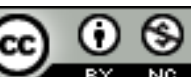

A e-Mosaicos Revista Multidisciplinar de Ensino, Pesquisa, Extensão e Cultura do Instituto de Aplicação Fernando Rodrigues da Silveira (CAp-UERJ) está disponibilizada sob uma Licença Creative Commons - Atribuição-NãoComercial 4.0 Internacional.

Os direitos autorais de todos os trabalhos publicados na revista pertencem ao(s) seu(s) autor(es) e coautor(es), com o direito de primeira publicação cedido à e-Mosaicos.

Os artigos publicados são de acesso público, de uso gratuito, com atribuição de autoria obrigatória, para aplicações de finalidade educacional e não-comercial, de acordo com o modelo de licenciamento Creative Commons adotado pela revista. 